\title{
'DON'T STARE AT ME....' EXPLORING THE LIVED EXPERIENCES OF ADULTS WITH DISABILITY
}

\author{
${ }^{1 *}$ Ritu Singh, ${ }^{2}$ Geeta Chopra \\ ${ }^{1,2}$ Institute of Home Economics, University of Delhi, India
}

\begin{abstract}
The spirit of rights based approach calls for the meaningful involvement of people with disabilities in daily aspects of life and their participation is crucial if we want to build an inclusive and prosperous society. For achieving the aim of inclusion it becomes necessary to go by the slogan of disabled people's organizations i.e. "Nothing about us, without us"; this further defines the purpose of present paper which locates the perspectives of people with disabilities in terms of what it means to live with a disability. Much has been focussed on the opinions of caregivers when it comes to talking about people with disabilities thus keeping aside the insider's perspectives of living the phenomenon of disability. The lived experiences of people with disabilities is the need of an hour when across the globe thrust in on inclusion. The paper explores the identity, self-concept, self-consciousness, participation, sexuality, barriers, and employment, all seen through the eyes of the adults with disability. The adults with disabilities feel themselves as normal, want to be included by participating in social and economic domains and explore sexuality as non-disabled people; it is the presence of the barriers in social and environmental zones that hinder their inclusion. The databases searched included Google Scholar, Science Direct, Scopus, Elsevier, Proquest, Springer, and Sage; also the reference lists of journal articles were located.
\end{abstract}

Keywords: disability; self-concept; identity; sexuality; participation; employment

\section{Introduction}

The voices of persons with disabilities is of paramount significance as they pave the way for planning of effective policies and to determine programmes which are as per their needs and effective in ameliorating the difficulties that they face. Going by the disability anthem 'Nothing for us without us', this paper brings to fore the voices of adults with disabilities and presents their lived experiences The paper would give a peek into the lives of persons with disabilities and how they perceive and encounter the phenomenon of living with a disability.

Living with a disability is beset with both positive and negative aspects (Tagaki 2016). Studies have documented that people with disabilities are confronted with experiences of discrimination, stigmatization in

\footnotetext{
* Corresponding author: Ritu Singh

ritu21singh89@gmail.com

Published online at http://IJDS.ub.ac.id/

Copyright $\odot$ 2018PSLD UB Publishing. All Rights Reserved
}

terms of attitudinal barriers, negative labelling, and prejudices in their daily encounters with able-bodied counterparts (Baffoe 2013; Cardona 2013; Deepak et al. 2016; Gallagher et al. 2011; Gartrell 2010; Haggstrom and Lund 2008; Islam 2008; Koka-Atabey 2013; Lin, Knox, and Barr 2014; Lundberg et al. 2011; Mattevi et al. 2012; Norlyk, Martinsen, and Kjaer-Petersen 2013; Pande and Tiwari 2011; Papadimitriou 2008; Price et al. 2011; Rule and Modipa, 2012; Taub, McLorg, and Bartnick et al. 2009; Tijm, Cornielje, and Edusei 2011). Papadimitriou (2008) reported that individual with disabilities spoke of feeling different and being devalued, as expressed in verbatim of one woman participant:

it's as if now that I am in a chair it doesn't matter if I am educated, pretty, if I work, rock climb, or anything. All that matters is that I am different looking. And don't get me wrong, I am different! But not in the way that people seem to think of me [as different]. Of course I am different. I was going down the stairs of my friend's apartment building and I 
fell and broke my back! But, you know, I am the same Jennifer I was before the accident. It's still me; it's a different body. (Papadimitriou 2008, 699-700)

Research has found that people with disabilities encounter experiences of unfriendly, hostile gaze that invade their minds and give them the sense of negative perception about them and make them feel as a non-existent entity (Baffoe 2013; Gibson et al. 2007; Islam 2008; Sheldon, Renwick, and Yoshida 2011). Disabled people lamented the fact that it is their impairment which is observed first rather than their identity as a person on basis of their abilities (Norlyk et al. 2013; Payne et al. 2016; Kattari 2014; Papadimitriou 2008; Wedgwood 2011).

People with disabilities have adopted strategies to overcome the attitudinal barriers in form of stigma or negative perceptions from able-bodied and to define meaning in their lives (Deepak et al. 2016; Gibson et al. 2007; Lin et al. 2014; Loja et al. 2013; Lundberg et al. 2011).

Disability is viewed in positive frame and challenges of daily living are appreciated (Sheldon et al. 2011; Stromso 2008). The positive side of disability is emphasized as one participant with acquired impairment shared:

I no longer think about my disability because I have come to believe that this is part of life. The only thing is to try to learn how to live with it. If it has come, it has come, and I cannot do away with it. The only solution is to live with it, and I never regret that. I only now struggle to live positively with my impairment (Stromso 2008, 99-100)

The World Report on Disability (2011) accounts for more than a billion or $15 \%$ of the world's population living with some form of disability (WHO 2011). This indicates a huge number and if we think of prosperous developing society we cannot ignore the people with disabilities; instead we should plan to include the opinions of people with disabilities in planning inclusive set up by adhering to the principles of the United Nations Convention on the rights of Persons with Disabilities (UNCRPD) that lays thrusts on meaningful participation of people with disabilities (WHO 2011). The involvement of people with disabilities makes it necessary to have their voices heard and thus justifying the purpose of the review.

\section{Methodology}

For the review of the literature, electronic database searches were made by browsing search engines like Google Scholar, Proquest, Elsevier, Springer, Sage, Science Direct and Scopus. The keywords utilized for the search included lived experiences, people with disabilities, self-concept, identity, sexuality, participation, employment; the combination of words using 'and' or distinguishing the keywords by using comma was searched. The inclusion criteria for the studies was the original research studies employing qualitative involving voices of people with disabilities and located in the time period within the range of 2007-2017. The exclusion criteria involved excluding the studies that involved quantitative methods and caregiver's perspectives. The studies were filtered by reading the abstracts and if found relevant full article was read and thus included.

\section{Findings}

The studies located on the basis of keywords were maintained in the respective folders and then read several times and thus summarised in different sections.

\section{Disability, Self-Concept, and Identity}

Self-concept is defined as what an individual thinks about the self; basically, the beliefs held by an individual regarding his or herself and include the person's qualities. Identity is defined as knowledge of the self that an individual holds which is build-up of values, beliefs and goals (Berk 1997).

Self is experienced in a positive frame by people with learning disabilities across different domains of self-concept like social, physical, occupational, cultural or psychological self-perceptions. In terms of physical appearance negative self is reported. In terms of social self, participants identified themselves as supportive, friendly and helpful (Pestana 2014). In the study by Saltes (2013) few participants did feel positive about the impairment in terms of self and finds no issue in disclosing the impairment, as shared by one of them:

Cite this as:

Singh, Ritu, Chopra, Geeta. 'Don't Stare At Me....' Exploring The Lived Experiences Of Adults With Disability. Indonesian Journal of Disability Studies (IJDS).2018: Vol. 5(1): PP 10 - 25. 
'I believe in honesty and have no problem whatsoever disclosing my disability'; and 'I don't mind because I am very confident. I'm beautiful, educated, independent, and very humorous.' (Saltes 2013, 105)

The self is not impacted by negative perceptions held by able-bodied and can be distinguished from impairment (Loja et al. 2013; Parker and Yau 2012). As noticed in the study by Parker and Yau (2012) where a woman with spinal cord injury does not let her impairment affects the sense of self as she stated:

'I don't really see the wheelchair or anything like that. But it obviously affects other people. But I have come to deal with that and it's their problem, not mine. If they can't be there [because of the disability], then I don't want them there.' (Parker and Yau 2012, 21)

The gaze of able-bodied was found to impact the self as found in the study of men with spinal cord injury, as described by one man:

'People staring at you. You don't even know who you are anymore, you know, because it is, it totally changes you from what you were to what you are, and people look at you that way too.' (Sheldon et al. 2011, 311)

Embodied self is viewed as negative or ingrained in self (Loja et al. 2013; Stromso 2008). Altered body image owing to disability is found to impact the sense of self as stated by a woman with spinal cord injury:

'I have lost my shape and my figure. So I don't really like the way my body looks.' (Parker and Yau 2012, 21)

The internalization of imposed identities and experiences of exclusion in the understanding of self is experienced in the study by Gibson et al. (2007), as expressed by a man with muscular dystrophy:

'Well, we have don't have anything to offer. No professional career. No real income. Even sexually in bed we can't offer a lot.' (Gibson et al. 2007, 511)

In the construction of disabled identity, bodily differences on account of impairment do have a role to play and identity is entangled in an intersection of bodily ideals, gender, and impairment. As reported by a woman with a physical disability:

E: What's the influence of your body on the person that you are? e: I think it has to do with the feminine vanity. I miss that part ... The heels and the dresses ... [laughing]. Of the power, of having more freedom of choice. Imagine, I am going out with a group of girlfriends and they are all dressed up, with their heels and dresses and of course, I feel different there. I wished I could be different. Not as much as in the past when I really got upset. (Loja et al. 2013, 199)

Stromso (2008) found that the lived experience of embodied self and identity formation is located in different social encounters and spaces in which the person is situated and a person can have multiple selves and identifies according to the context. As stated by one of the participants who acquired blindness in her teens who first internalized the imposed identity given by able-bodied and was negative, on becoming the mother she experienced a change in self as she expressed:

'I used to think of poisoning myself. Right now, when I think of my child, I cannot think of poisoning myself because I know I have to live for her, and she is also there for me. So at least now, she is my consolation'. (Stromso 2008, 92)

Persons with disabilities distanced themselves from the social positioning of categorizations as disabled or retarded and rejected the label of disability identity imposed on them (Cardona 2013; Le Clair 2011; Gustavsson, Nyberg, and Westin 2016; Taub et al. 2009; Valentim and Dinis 2014).

On-going tension occurs between an inward sense of embracing disability

Cite this as:

Singh, Ritu, Chopra, Geeta. 'Don't Stare At Me...' Exploring The Lived Experiences Of Adults With Disability. Indonesian Journal of Disability Studies (IJDS).2018: Vol. 5(1): PP 10 - 25. 
identity and presenting self as a normal in the public (Bagatell 2007; Cox et al. 2017). The on-going tension in identity domain as stated by one participant in his verbatim:

"Every day. . . . That was kind of what I was taught to do: . . you are to pass yourself off as normal as much as you can." (Cox et al. 2017, 80)

Disclosure of disabled identity is generally avoided by the people with disabilities; except when the circumstances call in for (Cox et al. 2017; Gustavsson et al. 2016). Persons with disabilities appeared to be apprehensive in disclosure of their disability identity as in the study by Kattari (2014) where a disabled woman expressed her state of apprehension regarding reaction of prospective partners on knowing about her disability as she said:

'I don't want to define my relationship by being someone who's disabled...I don't want to scare off someone who is able-bodied by talking too much about my disability, because to them it seems really scary.' (Kattari 2014, 506)

In Cooley's concept of the lookingglass self, the notion that individual develops self from the perceptions of others is well documented in the study done by Saltes (2013) as one participant in the study mentioned that:

how they react, or what they may think' was an influential factor in determining whether to keep or disclose their impairment'. (Saltes 2013, 101)

Disability is seen as belonging to them or a part of self-identity (Islam 2008; Saltes 2013). Disability is seen a part of self-identity as it is explicit from the statement made by a man when he was asked about his reaction on self-disclosure of the impairment:

'I feel very comfortable because this is part of who I am'. (Saltes 2013, 101)

Malini Chib, disability rights and author, who has cerebral palsy, asserts strong disability identity. She says that 'she wants to "celebrate" disability rather than reject. In the formulation of the identity of a disabled person, positive attitudes play a significant role. The disabled person should not deny his/her disability; instead, the difference needs to be celebrated. The acceptance of disability by a person with disability would enable to recognize his/her capabilities or limitations'. (Chib 2016)

The on-going tendency to reclaim 'person' and keeping aside the label of disability is reported in the study of a person with Down syndrome:

'The Down's is a nickname. I put it on one side, and then, I am me.' 'The Down's is another. I am Rafael'. (Almendros and Almendros 2015, 108)

Life stories of people with intellectual disability in the study affirm the notion of fluidity and flexibility in terms of 'self-identities' (Gustavsson et al. 2016).

Lundberg et al. (2014) found that identity was negotiated on account of disabled people's participation in adaptive sports and recreation activities as these served as a setting for change in identity, enhancing self-knowledge of the participants as in to do tasks independently, development of social networks, and acquisition of skills that helped them in discovering their selves. As one participant with paraplegia expressed:

'It's only been through my disability and perhaps my participation in sports and recreation as a disabled person that $I$ gained true self confidence...I had come to learn that I am not my body, I'm not my physically body, there is more to me than that.' (Lundberg et al. 2011, 214)

In order to have an enhanced self and to build a positive identity, the people with disabilities tend to negotiate by becoming self-reliant (Stromso 2008). To evolve out of a disability identity and negative labeling, involvement in continuous work is reported by men with muscular dystrophy (Gibson et al. 2007).

\section{Disability and Sexuality}

Sexuality is a central aspect of being human throughout life and encompasses

Cite this as:

Singh, Ritu, Chopra, Geeta. 'Don't Stare At Me....' Exploring The Lived Experiences Of Adults With Disability. Indonesian Journal of Disability Studies (IJDS).2018: Vol. 5(1): PP 10 - 25. 
sex, gender identities, and roles, sexual orientation, eroticism, pleasure, intimacy, and reproduction. Sexuality is experienced and expressed in thoughts, fantasies, desires, beliefs, attitudes, values, behaviors, practices, roles and relationships. While sexuality can include all of these dimensions, not all of them are always experienced or expressed. Sexuality is influenced by the interaction of biological, psychological, social, economic, political, cultural, ethical, legal, historical, religious and spiritual factors (WHO 2002).

People with disabilities are seen as either sexually inactive or like sex too much or asexual beings and owing to such myths they are deprived of sexual education (Hanass and Hancock 2009; Peta et al. 2016). The issue of sexual activity or bearing children is discouraged for the persons with disabilities and thus they are deprived of sex education by their families and sexual knowledge is considered potentially harmful or unnecessary (McKenzie 2013). The lack of sexual counselling or no education in terms of physiological or emotional aspects of sexuality was identified by women with women disabilities. They wanted health professionals to bring up issues of sexuality and to be open about it (Parker and Yau 2012).

Persons with disabilities denied and challenged the prevalent myth of asexuality as found in the research (McKenzie 2013; Payne et al. 2016; Peta et al. 2016; Wheeler 2007). In relation to this myth of asexuality, men with learning disabilities affirmed that learning disability in no way marks them as asexual or labels them with no sexual urges; as one participant expressed: 2007, 20)

'I do get $a$, a hard on'. (Wheeler

McKenzie (2013) found that people with disabilities affirm their worth by being engaged in intimate relations, getting married, bearing children and thus breaking the shackles of deep-rooted myths which were confronted by the participants in their environment. As expressed by a woman with congenital blindness that her pregnancy occurred as a surprise to her mother, as she said:

'Because, she didn't understand that I will understand the sex because she saw me as the little baby. I know nothing about the sex. I know nothing about the boyfriend. I know nothing. She was amazed when she saw me pregnant.' (McKenzie 2013, 380)

Amidst the oppressive and discriminative domains of sexual culture, in the study by Liddiard (2014) people with disabilities reported to be engaged in 'work' as mentioned in the study in order to affirm their sexuality; as expressed by a woman with congenital impairment:

being in a relationship is a constant reassurance in my worth as a person and a woman'. (Liddiard 2014, 120)

The sexual self of the people with disabilities is either not recognized or restrained by societal attitudes (Sakellariou 2012). Family interference was reported by the disabled people as the reason for denial of sexual autonomy or sexual engagement and thus their choice to indulge in dating or sexual contact was limited (Bernert 2011; Mc Kenzie 2013). The restriction in matters of sexuality with respect to dating was expressed by women with a mild intellectual disability that her date nights were being supervised by agency people so she didn't have sex, as she stated:

I have to be around where staff can make sure everythin's goin' OK. They come back and forth and check up on me, and make sure I don't do anything wrong. Like fool around the wrong way. Can't have sex. If you do that stuff, he'll have to go home, and I'll have to go to my room and spend the rest of the night there. (Bernert 2011, 136)

Peta et al. (2016) found that women with disabilities act as active agents in expressing their sexuality by being dynamically involved in intimate relations, asserting their sexuality as not just sex object what males assume, but affirming

Cite this as:

Singh, Ritu, Chopra, Geeta. 'Don't Stare At Me....' Exploring The Lived Experiences Of Adults With Disability. Indonesian Journal of Disability Studies (IJDS).2018: Vol. 5(1): PP 10 - 25. 
their choice by demanding love from their partners or using of herbs on vagina to enhance eroticism or bearing children and, thus challenging the stereotypes about disabled women. The desire to be independent in choosing partners, engaging in intimate relations or maintaining abstinence was reported among women with intellectual impairment. Despite restrictions on sexual activity, these women exhibit protective behaviours to engage in sexual encounters and were aware of utilising protective means like condoms, oral contraceptives (Bernert 2011).

Sakellariou (2012) found that men who acquired spinal injury negotiated sexuality as they adapted their ways in expressing sexual expression and the use of technologies in order to take care of their self. Parker and Yau (2012) found the role of adjustment and adaptation in managing sexual expressions by the stimulation of hypersensitive or non-genital areas, by being creative or having open communication to talk about needs and limitations in order to accommodate sexual needs of the self and partner is documented by women with spinal cord injury. As one participant mentioned:

'We do a fair bit of experimenting...it keeps it fairly interesting. It does not just have to be intercourse.' (Parker and Yau 2012, 19)

Kattari (2014) found that women with disabilities reported the role of partners in terms of communicating with them on needs around sexuality and disability that aids in enhancing sexual satisfaction and adaptations in terms of sexual expression and to be 'kinky' in expressing themselves in sexual interaction. As one woman expressed the role of partner connection that channelized her intimacy as she said: ... if I'm totally upfront with a partner, which I am now with a romantic partner, I think my sexual satisfaction increases, not only because they understand me, and my body, and what my limits are, and that they can change, but also just that confidence to be able to talk about my body in a really honest and direct way has led to increased sexual satisfaction. (Kattari 2014, 506)

The urge to be recognized beyond the impairment and to divert the attention of onlooker from their bodies as they employed certain tactics is reported in the study by Payne et al. 2016; as the woman stated that by wearing bright red shoes she was able to divert the attention of viewer from her disability and the process began with complimentary note as she said:

'The conversation begins with something complimentary - not what's wrong with you, but something that's nice about you - rather than understanding the problem before the person.' (Payne et al. 2016, 1036)

The barriers in terms of sexuality due to changes in body image post injury, difficulty in finding a prospective partner and maintaining fulfilling intimate relationships, limited sexual knowledge or lack of sexual counseling, negative perceptions of a non-disabled and lack of spontaneity in sexual activity is documented in the study by Parker and Yau 2012. To prepare oneself for sexual activity and to manage the arrangements prior to sexual activity is shared by a woman with spinal cord injury:

The whole spontaneity has to go out the door because everything is planned...I can't get up and run to him to give him a cuddle or if he has go this back to me somewhere I can't just go up to him and give him a cuddle and a kiss. I can come up to him, but it is predictable, because I am there. So it is not a surprise and it is not spontaneous. (Parker and Yau 2012, 22)

\section{Disability and Participation}

The International Classification of Functioning, Disability, and Health (ICF) describes participation as 'involvement in life situations' or as 'the lived experiences' of people in the actual context in which

Cite this as:

Singh, Ritu, Chopra, Geeta. 'Don't Stare At Me....' Exploring The Lived Experiences Of Adults With Disability. Indonesian Journal of Disability Studies (IJDS).2018: Vol. 5(1): PP 10 - 25. 
they live and does not discriminate between activity and participation in its coding (WHO 2001).

Participation is viewed as a set of values where individuals are free to choose activities in which sense of being valued is felt, feeling of personal growth, trust and a person feels a sense of control as expressed by the individuals with spinal cord injury (Velde et al. 2010). In the study by Ripat and Woodgate (2012), people with spinal cord injury described participation as an 'experience' instead of defining it on the basis of type or number of activities. Participation is seen as a settlement in terms of a body-environment interface, as in to feel included or belonged to activity or to have a sense of control over activity and to feel accomplished. As one participant expressed participation to be reciprocal as she said:

'it's dealing with ways or possibly improving your community and enriching, not only your own life, but other people's.' (Ripat and Woodgate 2012, 911)

People with disabilities marked their presence in participation by visiting the places of worship, recreational centers, and other contexts. The most preferred forms of participation reported were self-chosen activities with a higher degree of autonomy, in spaces where a sense of membership and to feel belonged is felt. Contexts of participation were given importance where the people with disabilities could escape stares of the public, could feel comfortable and open up their inner selves (Milner and Kelly 2009). Participation is preferred among people with disabilities to have commonness of beliefs (Milner and Kelly 2009; Taub et al. 2009). Lundberg et al. (2011) has discovered that participation in sports and recreation activities by people with disabilities has resulted in challenging their negative self-perceptions, as they reported building of social support, to feel normal, and compared themselves positively from others who were nondisabled and sensed freedom; as one participant appreciate the peer support that resulted out of participation in recreation activity as he said:

I think it has given me the knowledge that, hey you are not the only one in this situation. There are others in this situation, perhaps even worse than you, or better than you, but there are others experiencing this challenge in life along with you. The support system is huge! And just knowing there are others out there you can lean on is a great thing. (Lundberg et al. 2011,213)

The experience of participation is felt when things were done independently with satisfaction in accordance with own preferences in an environment where the individuals felt belonged to and valued, and also by being part of those activities where they advised and received contribution in lieu of it as reported by people with spinal cord injury (Haggstrom and Lund 2008). Gibson et al. (2007) discovered that the men with muscular dystrophy have placed significance in being 'out of home' in terms of meeting a friend, going for a walk, visiting relatives or being on their own in a neighborhood. Tagaki (2016) found that to be involved in activities like work be it social or welfare activities, child rearing, and leisure activities was accounted as meaningful in the lives of the people with disabilities and a sense of fulfilling was achieved. People with disabilities reported meaningful aspects of participation as their participation in adaptive sports and recreation activities has instilled in them the sense of independence, feeling of being normal as they too can do tasks, development of social networks, feeling of accomplishment on completion of tasks which further their confidence level and thus giving them sense of being at par as their non-disabled counterparts. As expressed by a woman with cerebral palsy who talks of success as meaningful outcome of participation:

"You are seeing success. You are accomplishing goals. You are doing 
something, so your confidence level is increasing". (Lundberg et al. 2011, 213)

Participation, be it in social space or in other domains of daily living, was found to be meted out by the barriers, which include environmental in terms of social, cultural or attitudinal, in terms of negative perceptions or stereotypes, prejudices, stigmatized notions or discriminatory labels from a non-disabled, inaccessible built environment, inaccessible transportation or toilets or on part of a personal or activity limitations is identified by the disabled persons (Baffoe 2013; Deepak et al. 2016; Gallagher et al. 2011; Haggstrom and Lund 2008; Islam 2008; Loja et al. 2013; Milner and Kelly 2009; Ripat and Woodgate 2012; Stromso 2008; Tijm et al. 2011). Inaccessibility in terms of the built environment acted as a barrier to participation in terms of socializing with friends or family as reported by people with a spinal cord injury (Price et al. 2011). Stromso (2008) found that the physical environment in terms of buildings, transport, assistive devices, safety, traffic etc. has posed barriers for opportunities of participation in the society as expressed by people with disabilities. Loja et al. (20130 found that participation in social life was thwarted on account of an unfriendly gaze that highlighted the negative discourses of an able-bodied as summed up by one participant:

I avoid going to public places. E: May I ask why? e: Maybe I haven't adjusted well yet. I am better now because until now I've been running from those places because of the gazes. [...] E: If there weren't the gazes, would it be easier for you to go out? e: Yes, if we were simply ignored and only seen as normal people. I would go out much more. (Loja et al. 2013, 196)

Social life too is beset with barriers present in the physical built environment such as inaccessible spaces or toilets or attitudinal ones or owing to physical limitations (Price et al. 2011; Taub et al.
2009). As one participant summed up how she deters her social engagements owing to physical barriers as she says:

I've tried to have a normal social life, but ... taking the wheelchair in and out of places, it's not a very pleasant thing to do - the fact of inaccessibility ... . I never really ever went to parties because of the people running in and out ... . I might break a bone or I might get hit or shoved accidentally. (Taub et al. 2009, 206)

Haggstrom and Lund (2008) found that disabled people devised strategies to enhance participation by doing things in novel ways, to take up the voluntary task or doing things for others or being part of activities that create a sense of belongingness in them. Stromso (2008) found that barriers to participation are negotiated by the impaired people in order to be a part of the inclusive place. As one person with a walking impairment in the process of negotiation of relatives' expectations of his disabled body stated:

'My relatives thought me incapable of the work necessary. I showed them by going to the garden and dig with them'. (Stromso 2008, 79)

\section{Disability and Employment}

Employment is a crucial event in the life of an individual that makes the person self-reliant, economic independent, productive, imparts a sense of self-worth and a way to overcome from the stigmatized labels that are accorded on the basis of disability as stated by disabled people in the study (Cunnah 2015; Lamichhane 2012). Higher education as expressed by disabled people is the route to gainful employment and better socioeconomic status (Lamichhane 2012).

Across the globe, people with disabilities are found to be self-employed as entrepreneurs, farmers, teachers, doctors, technicians or assistants. People with disabilities are capable of doing any work as their non-disabled counterparts, provided the right atmosphere is provided to them. 
Lower employment and higher unemployment rates respectively is experienced among people with disabilities both in developed and developing nations. A lower rate of labor market participation is significant route through which disability gives way to poverty (WHO 2011).

The voices of people with disabilities in the studies that are reviewed do mention the barriers encountered in maintaining and securing jobs on the whole. Disability is one of the prominent factors and is described as an obstacle in securing and maintaining employment. The employers are found to have preconceived notions that persons with disabilities cannot do productive work. The labelling of disability thus tends to negate the skills and potential of the employees with disabilities tend to be ignored (Bualar 2014; Enoch et al. 2016; Punch, Hyde, and Power 2007; Shier, Graham, and Jones 2009; Vedeler 2014; Wilson-Kovacs et al. 2008; Wehbi and ElLahib 2007). Being disabled is one barrier that acts as a stumbling block and identified as a reason for workplace discrimination by an employer as stated by one participant:

I guess the biggest thing is, when I go to the interview I don't usually let the employer know that I'm in a chair. 'Cause I find that if I do, it might scare them off, or it might give them a reason to say, 'don't bother coming in'. I did experience that with one person. ... I had asked the person whether the workplace was wheelchair accessible. And they said that they would get back to me and they never did. (Shier et al. 2009, 67)

Barriers in terms of inaccessible built environment viz., poorly constructed roads, lack of disabled friendly toilets, lack of transportation, inaccessible buildings and poor infrastructure at workplaces are types of obstacles that pose hindrance in seeking and maintaining jobs for people with disabilities (Bualar 2014; Gartrell 2010; Enoch et al. 2016; Kim and Williams 2012; Lamichhane 2012; Newton, Ormerod, and Thomas 2007; Shier et al. 2009; Wehbi and
El-Lahib, 2007). The inaccessible environment was found to be one of the reasons for not applying for the jobs, as expressed explicitly in verbatim of one of the participants:

'I would not apply for a job in an inaccessible building; I have only applied for jobs that have been in accessible buildings'. (Newton et al. 2007, 615)

Bualar (2014) found that lack of proper infrastructure at a workplace, lack of disabled friendly toilets or transportation is well summed by women with physical disabilities. As stated by one woman who had quit her job because of lack of disabled friendly toilet, as she said:

I tried to adjust myself to the office layout but taking the wheelchair in and out of the toilet was not easy. When in the toilet, I could not manage it on my own. Sometimes, I needed help but I felt ashamed of my body. The office had very little money to reconstruct the toilet. I told this to my family and they asked me to stop working. (Bualar 2014, 189)

In terms of built environment, an example of good practice is found where certain features of the public sector buildings did help persons with disabilities, as one participant expressed:

'The hospital is great. Getting through clinics is fine, getting around the hospital is fine, toilets and lifts great.' (Newton et al. 2007, 617)

Attitudinal barriers in terms of negative attitudes of employers, discrimination by employers or rude behaviour of co-workers based on the impairments is cited as another hassle in securing and maintaining gainful employment (Bualar 2014; Cunnah 2015; Gartrell 2010; Enoch et al. 2016; Punch et al. 2007; Shier et al. 2009; Vedeler 2014; Wehib and El-Lahib 2007). In terms of attitudinal barriers, women with physical disabilities reported that employers focused on their impairments and physical appearance. As one wheelchair bound woman while planning to apply for a job

Cite this as:

Singh, Ritu, Chopra, Geeta. 'Don't Stare At Me....' Exploring The Lived Experiences Of Adults With Disability. Indonesian Journal of Disability Studies (IJDS).2018: Vol. 5(1): PP 10 - 25. 
for counter clerk, felt excluded as she described:

'When I got in and asked for an application form, a man came to me and told me that I might not be fit for office requirements because his company prefers non-disabled employees. Then I wheeled myself out, feeling out of place.' (Bualar 2014, 192)

Personal limitations on part of their health condition or illness is another reason which acts as a barrier in continuing job as quoted by people with disabilities (Bualar 2014; Enoch et al. 2016; Kim and Williams, 2012; Shier et al. 2009; Wehbi and El-Lahib 2007). The issues of inaccessible work environment too can pose a problem in continuing work as summed up by a participant who in spite of excelling in workplace was asked to leave as she mentioned:

My team moved office at the beginning of September so I have not been able to work for three and a half months, and there is no sign of things being right any time soon. Rather than deal with the access issues my employer has tried to retire or redeploy me. They are only doing this because I have mobility impairment. The Occupational Health people have said I am not sick and my employer has had to acknowledge my excellent record of not going off sick. Yet I am now off sick with my employer's agreement, even though I am not sick. (Newton et al. 2007, 616)

Wilson-Kovacs et al. (2008) found that people with disabilities do encounter lack of support from the organization in terms of providing them the opportunities to prove their potential or make the workplace adjustments or lack of knowledge regarding disability, thus affecting the career advancement of disabled workers. Difficulties were encountered in terms of seeking accommodations at the workplace (Kim and Williams 2012; Punch et al. 2007. The same plight is expressed by one participant:
For the past two years, I have been asking for accommodations in the form of a note taker. I have not gotten any because, you know, while they just assume that since they provide the schools with equipment, we, the teachers, could access that equipment ... Last year, two of my colleagues were able to get note-takers, but I didn't. (Kim and Williams 2012, 847)

Women with disabilities are more prejudiced against than men in employment sector besides the barriers faced in terms of negative attitudes or inaccessibility issues. Bualar (2014) found that women with disabilities reported that inaccessible job information was another reason that kept them aloof from seeking work; as most of the advertisements were on bulletin boards in radio stations or those of government buildings which are located in far flung places. The family is cited as a reason for their non-participation in labour market as their family feel over protective for these women or in case of women with intellectual disability the fear of these women getting injured or incapable of doing work as assumed by the family of a disabled woman (Bualar 2014; Wehbi and El-Lahib 2007). The family keeps women bound, as expressed by a woman who has a joint defect and said that her family appears to be over protective which is explicit in her statement:

My husband and sons are very worried about me when I ask them if I can work as a data recording employee at one of the local telecom companies. They do not feel comfortable letting me work outside our house. They fear that I might suffer from multiple injuries which I might experience if working outside. They strongly confirm that I should be at home. (Bualar 2014, 193)

Employers' positive perception regarding hiring of people with disabilities too was encountered in the study of job interview experiences by Vedeler (2014). As shared by a participant who did disclose her disability in the application and

Cite this as:

Singh, Ritu, Chopra, Geeta. 'Don't Stare At Me....' Exploring The Lived Experiences Of Adults With Disability. Indonesian Journal of Disability Studies (IJDS).2018: Vol. 5(1): PP 10 - 25. 
mentioned that employer first focused on her ability as she said:

He raised a few questions concerning 'what do you think we should do to accommodate your disability, like in case of a fire? We have offices on the fifth floor, so, are there measures we can implement without invading you in a sense?' [...] [they] had like an uncomplicated relationship to it [the impairment], not like, 'oh, you are disabled!' (Vedeler 2014, 606)

In the above example, positive experience is felt by the job aspirant and also the employer appeared to be keeping self in aspirant's shoes as the employer talked about what accommodations an aspirant expects.

The dilemma in terms of disclosure of a disability is found among the people with disabilities; as if mentioned in the resume it might amount to losing of job opportunity or confronting the attitudinal barrier by an employer in job seeking process (Shier et al. 2009; Vedeler 2014; Yee 2013).

To minimize the effects of discrimination, people with disabilities did plan coping strategies in terms of withdrawing themselves from people whom they believe would worsen their plight, next they rely on government initiative and policies (Enoch et al. 2016). Shier et al. (2009) mentioned the strategies to enhance work participation which came up from voices of the people with disabilities in the study that the employers and corporate sector people need to be made aware and educated about the understanding of persons with disabilities in order to create supportive work environment. In order to evade the discrimination and negative attitudes, they maintain a feeling of perseverance or are humorous as told by one participant:

'I try to be funny about it, when I say, 'yeah, I have a seizure disorder', you know. Yeah, just don't put any flashing lights in front of me; otherwise I'll start doing the funky chicken for you.' (Shier et al. 2009, 71)

\section{Conclusion}

The voices of adults with disabilities present an overview of their experiences of living with a disability and how they navigate the course of daily encounters of negative hegemony created by able-bodied. In terms of their experience of self and identity amidst the socially imposed discourses of stigmatization, exclusion and marginalization; the responses varied among people with disabilities as some tend to internalize the discriminatory beliefs held by non-disabled and accepted the imposed categorizations, while others appeared to embrace their disability identity and felt at peace while disclosing about their impairment, and few others maintained self and impairment as two separate identities. By and large it was found that the negative perceptions of nondisabled did have an impact on their identity and due to the stereotypes attached to the label of disability, the disabled people tend to dissociate from disability identity or indulge in practices that shield them from being tagged as disabled. To conclude the voices of adults with disabilities with regard to sexuality, again the common thread appeared to be of attitudinal barriers held by non-disabled that view disabled people as asexual and the findings affirm the experiences of disabled people being labelled as asexual and how they fight such stereotype. The stories depicted an altogether different picture whereby disabled people were found to be a dynamic agent in a sexual activity as they adapted their modes of sexual expression and embraced the partner support and process of being upfront in discussing their needs about sexuality. In order to resist the normative typology of asexuality myth, at times being in relationship is attached to their sense of selfworth. Participation was accorded importance by disabled people as it helped them in development of social support, helped them fighting the odd system values and avenue for creating meaning in lives. But the disabling stand is of an environment inhabited by the disabled people that acts as a hurdle in fuelling their lives to ecstasy and to be included; the barriers in terms of built environment and prejudices that not only hamper their community or social participation but they tend to stretch their fangs of venom in employment sector and thus disabling the work competence

Cite this as:

Singh, Ritu, Chopra, Geeta. 'Don't Stare At Me....' Exploring The Lived Experiences Of Adults With Disability. Indonesian Journal of Disability Studies (IJDS).2018: Vol. 5(1): PP 10 - 25. 
of the people with impairments Though physical limitation is another thing which imposed limitations in activities of daily living; but on the whole it is the societal dynamics deep rooted in normative postulates that gives no room to disabled people and thus creates a world of exclusion and apathy for person with disability.

There is a need to consider the voices of persons with disability when designing policies and programmes to build an accessible world for them.

\section{References}

Calderón-Almendros , Ignacio, and Rafael Calderón-Almendros. "I open the coffin and here I am': disability as oppression and education as liberation in the construction of personal identity." Disability \& Society 31, no. 1 (February 12, 2016): 100-15. Accessed March 21 , 2017. doi:10.1080/09687599.2015.1133400.

Baffoe, Michael. (2013). Stigma, Discrimination \& Marginalization: Gateways to Oppression of Persons with Disabilities in Ghana, West Africa . Journal of Educational and Social Research 3, no. 1 (January 2013): 187-98. Accessed April 08, 2017. doi: 10.5901/jesr.2013.v3n1p187.

Bagatell, Nancy. (2007). Orchestrating voices: autism, identity and the power of discourse. Disability \& Society 22, no. 4 (June 11, 2007): 413-26. Accessed May 02, 2017. doi:10.1080/09687590701337967.

Berk, Laura E. (1997). Self and Social Understanding." In Child Development. 4th ed. United States of America

Bernert, Donna J. (2010). Sexuality and Disability in the Lives of Women with Intellectual Disabilities. Sexuality and Disability 29 (December 09, 2010): 129-41. Accessed March 21, 2017. doi: 10.1007/s11195-010-9190-4.

Bualar, Theeraphong. "Barriers to employment: voices of physically disabled rural women in Thailand." Community, Work \& Family 17, no. 2 (June 08, 2013): 181-99. Accessed March 21, 2017. doi:10.1080/13668803.2013.806125.
Cardona, Gordon C. "Overcoming disabling barriers: disability and attitudes to disability within the Maltese context: an insider's perspective." Disability \& Society 28 , no. 2 (January 16, 2013): 279-84. Accessed March 21, $2017 . \quad$ doi:10.1 080/09687599.2012.753186.

Chib, Malini. "Celebrating Disabilities: Author Malini Chib Sheds New Light on Disability through Her Book." The Better India (web log), December 09, 2016. Accessed June 01, 2017. http://www.thebetterindia.com/77745/malinichib-discuss-why-celebrate-disability/.

Cox, Bradley E., Kerry Thompson, Amelia Anderson, Amanda Mintz, Taylor Locks, Lindee Morgan, Jeffrey Edelstein, and Abigail Wolz. "College Experiences for Students with Autism Spectrum Disorder: Public Identity, Public Disclosure, and Institutional Support." Journal of College Student Development 58, no. 1 (January 2017): 71-87. Accessed March 21, 2017. doi:10.1353/csd.2017.0004.

Cunnah, Wendy. "Disabled students: identity, inclusion and work-based placements." Disability \& Society 30, no. 2 (January 26, 2015): 213-26. Accessed March 21, 2017. doi:10.1080/09687599.2014.996282.

Deepak, Sunil, Jayanth Kumar, Cheluvaraju Sivarama, Ramesh Giriyappa, and Parthipan Ramaswamy. "Life stories of persons with intellectual disabilities in Mandya District, India." Knowledge Management for Development Journal, 2016, 8-24. Accessed February 26, 2017. http://journal.km4dev.org/.

"Defining sexual health." WHO. Accessed August 11, 2017. http://www.who.int/reproductivehealth/topics/s exual_health/sh_definitions/en/.

Enoch, Acheampong, Anthony Kwaku Edusei, Okyere Paul, Akohene Kofi Mensah, Rose Odotei Adjei, and Emmanuel AppiahBrempong2. "“We are not getting jobs": Job seeking Problems of People with Disability and Coping Strategies adopted in an Urban Traditional Community in Ghana." Disability, CBR and Inclusive Development 27, no. 1 (2016): 109-25. Accessed February 26, 2017. doi: 10.5463/DCID.v27i1.499.

Gallagher, Pamela, Mary-Ann O'Donovan, Anne Doyle, and Deirdre Desmond. "Environmental barriers, activity limitations

Cite this as:

Singh, Ritu, Chopra, Geeta. 'Don't Stare At Me....' Exploring The Lived Experiences Of Adults With Disability. Indonesian Journal of Disability Studies (IJDS).2018: Vol. 5(1): PP 10 - 25. 
and participation restrictions experienced by people with major limb amputation." Prosthetics and Orthotics International 35, no. 3 (2011):

$278-84$ doi:10.1177/0309364611407108.

Gartrell, Alexandra. "'A frog in a well': the exclusion of disabled people from work in Cambodia." Disability \& Society 25 , no. 3 (April 28, 2010): 289-301. Accessed May 09, 2017. doi: 10.1080/09687591003701207.

Gibson, Barbara E., Nancy L. Young, Ross E.g. Upshur, and Patricia Mckeever. "Men on the margin: A Bourdieusian examination of living into adulthood with muscular dystrophy." Social Science \& Medicine 65, no. 3 (2007): 505-17. Accessed May 12, 2017. doi:10.1016/j.socscimed.2007.03.043.

Gustavsson, Anders, Catarina Nyberg, and Charles Westin. "Plurality and continuityUnderstanding self-identity of persons with intellectual disability." European Journal of Disability Research 10 (October 15, 2016): 310-26. Accessed February 23, 2017. doi:10.1016/j.alter.2016.06.003.

Häggström, Anna, and Maria Larsson Lund. "THE COMPLEXITY OF PARTICIPATION IN DAILY LIFE: A QUALITATIVE STUDY OF THE EXPERIENCES OF PERSONS WITH ACQUIRED BRAIN INJURY." J Rehabil Med 40:89-95. Accessed March 21, 2017. doi: 10.2340/16501977-0138.

Hanass-Hancock, Jill. "Interweaving Conceptualizations of Gender and Disability in the Context of Vulnerability to HIV/AIDS in KwaZulu-Natal, South Africa." Sexuality and Disability 27, no. 1 (2008): 35-47. Accessed April 14, 2017. doi:10.1007/s11195-008-91059.

"International Classification of Functioning, Disability and Health (ICF)." World Health Organization. 2001. Accessed August 12, 2017. http://www.who.int/classifications/icf/en/.

Islam, Zoebia. "Negotiating identities: the lives of Pakistani and Bangladeshi young disabled people." Disability \& Society 23, no. 1 (December 05, 2007): 41-52. Accessed March 21, 2017. doi:10.1080/09687590701725625.

Kattari, Shanna K. "Sexual Experiences of Adults with Physical Disabilities: Negotiating with Sexual Partners." Sexuality and Disability
32 (September 25, 2014): 499-513. Accessed March 21, 2017. doi: 10.1007/s11195-0149379-z.

Kim, Mikyong Minsun, and Brenda C. Williams. "Lived employment experiences of college students and graduates with physical disabilities in the United States." Disability \& Society 27, no. 6 (April 30, 2012): 837-52. Accessed March 21, 2017. doi:10.1080/09687599.2012.673081.

Koca-Atabey, Müjde. "A personal validation of the social nature of disability: different environments, different experiences." Disability \& Society 28, no. 7 (August 20, 2013): 1027 031. Accessed March 21, 2017. doi:10.1080/09687599.2013.820535.

Lamichhane, Kamal . "Employment situation and life changes for people with disabilities: evidence from Nepal." Disability \& Society 27, no. 4 (March 22, 2012): 471-85. Accessed February 20, 2017. doi:10.1080/09687599.2012.659462.

Le Clair, Jill M. "Transformed identity: from disabled person to global Paralympian." Sport in Society 14, no. 9 (December 07, 2011): 1116-130. Accessed March 21, 2017. doi:10.1080/17430437.2011.614768.

Liddiard, Kirsty. "The work of disabled identities in intimate relationships." Disability \& Society 29, no. 1 (May 08, 2013): 115-28. Accessed March 21, 2017. doi:10.1080/09687599.2013.776486.

Lin, Hsiu-Ching, Marie Knox, and Jennieffer Barr. "A grounded theory of living a life with a physical disability in Taiwan." Disability \& Society 29, no. 6 (2014): 968-79. Accessed March 21, 2017. doi:10.1080/09687599.2014.902361.

Loja, Ema, Maria Emília Costa, Bill Hughes, and Isabel Menezes. "Disability, embodiment and ableism: stories of resistance." Disability \& Society 28, no. 2 (August 01, 2012): 190-203. Accessed May 01, 2017. doi:10.1080/09687599.2012.705057.

Lundberg, Neil R., Stacy Taniguchi, Bryan P. McCormick, and Catherine Tibbs. "Identity Negotiating: Redefining Stigmatized Identities through Adaptive Sports and Recreation Participation among Individuals with a

Cite this as:

Singh, Ritu, Chopra, Geeta. 'Don't Stare At Me....' Exploring The Lived Experiences Of Adults With Disability. Indonesian Journal of Disability Studies (IJDS).2018: Vol. 5(1): PP 10 - 25. 
Disability." Journal of Leisure Research 43, no. 2 (2011): 205-25. Accessed April 25, 2017.

Mattevi, Betina S., Juliana Bredemeier, Cláudia Fam, and Marcelo P. Fleck. "Quality of care, quality of life, and attitudes toward disabilities: perspectives from a qualitative focus group study in Porto Alegre, Brazil." Revista Panamericana de Salud Pública 31, no. 3 (2012): 188-96. Accessed May 1, 2017. doi:10.1590/s1020-49892012000300002.

McKenzie, Judith Anne. "Disabled people in rural South Africa talk about sexuality." Culture, Health \& Sexuality 15, no. 3 (December 11, 2012): 372-86. Accessed April 12, 2017. doi: 10.1080/13691058.2012.748936

Milner, Paul, and Berni Kelly. "Community participation and inclusion: people with disabilities defining their place." Disability \& Society 24, no. 1 (January 15, 2009): 47-62. Accessed February 20, 2017. doi:10.1080/09687590802535410.

Newton, Rita, Marcus Ormerod, and Pam Thomas. "Disabled people's experiences in the workplace environment in England ." Equal Opportunities International 26, no. 6 (2007): 610-23. Accessed May 03, 2017. doi:10.1108/02610150710777079.

Norlyk, Annelise, Bente Martinsen, and Klaus Kjaer-Petersen. "Living with clipped wingsPatients' experience of losing a leg." International Journal of Qualitative Studies on Health and Well-being 8, no. 1 (October 14, 2013): 21891. Accessed April 29, 2017. doi:10.3402/qhw.v8i0.21891.

Pande, Namita, and Shruti Tewari. "Understanding Coping with Distress due to Physical Disability ." Psychology and Developing Societies 23, no. 2 (2011): 177-209. Accessed April 16, 2017. doi: 10.1177/097133361102300203.

Papadimitriou, Christina. "Becoming en-wheeled: the situated accomplishment of re-embodiment as a wheelchair user after spinal cord injury." Disability \& Society 23 , no. 7 (December 03, 2008): 691-704. Accessed April 08, 2017. doi:10.1080/09687590802469420.

Parker, Malorie G., and Matthew K. Yau. "Sexuality, Identity and Women with Spinal Cord Injury." Sexuality and Disability 30 (July
10, 2011): 15-27. Accessed April 13, 2017. doi: 10.1007/s11195-011-9222-8.

Payne, Deborah Ann, Huhana Hickey, Huhana Nelson, Katherine Rees, Henrietta Bollinger, and Stephanie Hartley. "Physically disabled women and sexual identity: a PhotoVoice study." Disability \& Society 31 , no. 8 (September 29, 2016): 1030-049. Accessed March 21, 2017. doi:10.1080/09687599.2016.1230044.

Pestana, Claudio. "Exploring the self-concept of adults with mild learning disabilities." British Journal of Learning Disabilities 43 (2014): 1623. Accessed March 21, 2017. doi:10.1111/bld.12081.

Peta, Christine , Judith McKenzie, Harsha Kathard, and Adelene Africa. "We are Not Asexual Beings: Disabled Women in Zimbabwe Talk About Their Active Sexuality." Sexuality Research and Social Policy, November 02, 2016. Accessed February 23, 2017. doi: 10.1007/s13178-016-0266-5.

Price, Pollie, Stephanie Stephenson, Lesha Krantz, and Kristine Ward. "Beyond My Front Door: The Occupational and Social Participation of Adults With Spinal Cord Injury ." Occupation, Participation and Health 31, no. 2 (2011). Accessed May 12, 2017. doi:10.3928/15394492-20100521-01.

Punch, Rene 'e , Merv Hyde, and Des Power. "Career and Workplace Experiences of Australian University Graduates Who Are Deaf or Hard of Hearing." Journal of Deaf Studies and Deaf Education 12, no. 4 (April 29, 2007): 504-17. Accessed May 02, 2017. doi:10.1093/deafed/enm011.

Ripat, JD, and RL Woodgate. "Self-perceived participation among adults with spinal cord injury: a grounded theory study." Spinal Cord 50 (July 03, 2012): 908-14. Accessed May 12, 2017. doi:10.1038/sc.2012.77.

Rule, Peter, and Taadi Ruth Modipa. "“We Must Believe in Ourselves": Attitudes and Experiences of Adult Learners With Disabilities in KwaZulu-Natal, South Africa." Adult Education Quarterly 62, no. 2 (2012): 138-58. Accessed April 25, 2017. doi:10.1177/0741713611400303.

Sakellariou, Dikaios. "Sexuality and Disability: A Discussion on Care of the Self." Sexuality

Cite this as:

Singh, Ritu, Chopra, Geeta. 'Don't Stare At Me....' Exploring The Lived Experiences Of Adults With Disability. Indonesian Journal of Disability Studies (IJDS).2018: Vol. 5(1): PP 10 - 25. 
and Disability 30 (July 01, 2011): 187-97. Accessed March 21, 2017. doi: 10.1007/s11195-011-9219-3.

Saltes, Natasha. "Disability, identity and disclosure in the online dating environment." Disability \& Society 28, no. 1 (June 12, 2012): 96-109. Accessed March 21, 2017. doi:10.1080/09687599.2012.695577.

Sheldon, Ann Popowich, Rebecca Renwick, and Karen K.Yoshida. "Exploring Body Image and Self-Concept of Men With Acquired Spinal Cord Injuries." American Journal of Men's Health 5, no. 4 (2011): 306-17. Accessed April 25, 2017. doi: 10.1177/1557988310375714.

Shier, Michael, John R. Graham, and Marion E. Jones. "Barriers to employment as experienced by disabled people: a qualitative analysis in Calgary and Regina, Canada." Disability \& Society 24, no. 1 (January 15, 2009): 63-75. Accessed February 20, 2017. doi: 10.1080/09687590802535485.

Strøms $\varnothing$, Mette. Places of Participation - The Lived Experience of Persons with Disabilities in Kampala/Uganda . Master's thesis, Norwegian University of Science and Technology - NTNU , 2008. Trondheim, 2008. 1-131. Accessed May 27, 2016.

Tagaki, Masakuni. "Narratives of Ambivalent Meanings of Acquired Physical Disability in Japan." SAGE Open, 2016. Accessed February 26, 2017. doi:10.1177/2158244016666310.

Taub, Diane E., Penelope A. McLorg, and April K. Bartnick. "Physical and social barriers to social relationships: voices of rural disabled women in the USA." Disability \& Society 24, no. 2 (March 11, 2009): 201-15. Accessed March 21, 2017. doi:10.1080/09687590802652496.

Tijm, Mandy M., Huib Cornielje, and Anthony Kwaku Edusei. "'WELCOME TO MY LIFE!' PHOTOVOICE: NEEDS ASSESSMENT OF, AND BY, PERSONS WITH PHYSICAL DISABILITIES IN THE KUMASI METROPOLIS, GHANA ." Disability, CBR and Inclusive Development 22, no. 1 (2011): 55-72. Accessed February 22, 2017. doi: 10.5463/DCID.v22i1.12.

Valentim, Joaquim, and Edite Dinis. "The Image of Disability Among Intellectually Disabled People ." Papers on Social
Representations 23 (2014): 24.1-4.17. Accessed February 22 , 2017. http://www.psych.lse.ac.uk/psr/.

Vedeler, Janikke Solstad. "Disabled persons' job interview experiences: stories of discrimination, uncertainty and recognition." Disability \& Society 29, no. 4 (November 29, 2013): 597-610. Accessed March 21, 2017. doi:10.1080/09687599.2013.831748.

Velde, Dominique Van de, Piet Bracke, Geert Van Hove, Staffan Josephsson, and Guy Vanderstraeten. "Perceived participation, experiences from persons with spinal cord injury in their transition period from hospital to home." International Journal of Rehabilitation Research, July 2010. Accessed May 12, 2017. doi:10.1097/MRR.0b013e32833cdf2a.

Wedgwood, Nikki. "A Person with Abilities: The Transition to Adulthood of a Young Woman with a Severe Physical Impairment." Young 19, no. 4 (2011): 434-54. Accessed May 09, 2017. doi:10.1177/110330881101900405.

Wehbi, Samantha, and Y. El-Lahib. "The employment situation of people with disabilities in Lebanon: challenges and opportunities." Disability \& Society 22 , no. 4 (June 11, 2007): 371-82. Accessed May 03, 2017. doi:10.1080/09687590701337736.

Wheeler, Paul. "I Count Myself as Normal, Well, not Normal, but Normal Enough' Men with Learning Disabilities Tell their Stories about Sexuality and Sexual Identity ." Tizard Learning Disability Review 12, no. 1 (January 2007): 16-27. Accessed May 12, 2017. doi:10.1108/13595474200700003.

Wilson-Kovacs, Dana, Michelle K. Ryan, S. Alexander Haslam, and Anna Rabinovich. "'Just because you can get a wheelchair in the building doesn't necessarily mean that you can still participate': barriers to the career advancement of disabled professionals." Disability \& Society 23, no. 7 (December 03, 2008): 705-17. Accessed April 24, 2017. doi:10.1080/09687590802469198.

"World report on disability." World Health Organization. Accessed June 08, 2017. http://www.who.int/disabilities/world report/20 $\underline{11 / \mathrm{en} /}$

Cite this as:

Singh, Ritu, Chopra, Geeta. 'Don't Stare At Me....' Exploring The Lived Experiences Of Adults With Disability. Indonesian Journal of Disability Studies (IJDS).2018: Vol. 5(1): PP 10 - 25. 
Yee, Michelle Jean. Lived Experiences of SanFrancisco, 2013. 1-167. Accessed May Women with Hidden Disabilities: A 27 2016. Phenomenologically Based Study . Master's http://repository.usfca.edu/diss.References thesis, University of San Francisco, 2013. 